Marquette University

e-Publications@Marquette

Biological Sciences Faculty Research and

Publications

Biological Sciences, Department of

$9-2012$

\title{
The Ranging Costs of a Fallback Food: Liana Consumption Supplements Diet but Increases Foraging Effort in Howler Monkeys
}

Jacob C. Dunn

University of Cambridge

Norberto Asensio

Mahidol University

Victor Arroyo-Rodriguez

Universidad Nacional Autónoma de México

Stefan A. Schnitzer

Marquette University, stefan.schnitzer@marquette.edu

Jurgi Cristóbal-Azkarate

Universidad Veracruzana

Follow this and additional works at: https://epublications.marquette.edu/bio_fac

Part of the Biology Commons

\section{Recommended Citation}

Dunn, Jacob C.; Asensio, Norberto; Arroyo-Rodriguez, Victor; Schnitzer, Stefan A.; and Cristóbal-Azkarate, Jurgi, "The Ranging Costs of a Fallback Food: Liana Consumption Supplements Diet but Increases Foraging Effort in Howler Monkeys" (2012). Biological Sciences Faculty Research and Publications. 794.

https://epublications.marquette.edu/bio_fac/794 
Marquette University

e-Publications@Marquette

\section{Biological Sciences Faculty Research and Publications/College of Arts and Sciences}

This paper is NOT THE PUBLISHED VERSION; but the author's final, peer-reviewed manuscript. The published version may be accessed by following the link in the citation below.

Biotropica, Vol. 44, No. 5 (September 2012): 705-714. DOI. This article is (C) Wiley and permission has been granted for this version to appear in e-Publications@Marquette. Wiley does not grant permission for this article to be further copied/distributed or hosted elsewhere without the express permission from Wiley.

\section{The Ranging Costs of a Fallback Food: Liana Consumption Supplements Diet but Increases Foraging Effort in Howler Monkeys}

Jacob C. Dunn

Primate Immunogenetics and Molecular Ecology Research Group, Department of Biological Anthropology, University of Cambridge, Pembroke Street, Cambridge, CB2 3QY, U.K Laboratorio de Salud de Fauna Silvestre, Centro de Investigaciones Tropicales, Universidad Veracruzana, Siete de Enero \#12, Col. Felipe Carrillo Puerto, Xalapa, CP 91080 Veracruz, Mexico Norberto Asensio

Conservation Genetics and Ecology Group, Institute of Molecular Biosciences, Mahidol University, Bangkok, Thailand

The Monitoring and Surveillance Center for Zoonotic Diseases in Wildlife and Exotic Animals, Faculty of Veterinary Science, Mahidol University, Bangkok, Thailand Faculty of Environment and Resource Studies, Mahidol University, Bangkok, Thailand Victor Arroyo-Rodríguez 
Laboratorio de Ecología de Paisajes Fragmentados, Edificio Sur, Centro de Investigaciones en Ecosistemas, Universidad Nacional Autónoma de México, Michoacán, Morelia, Mexico

\section{Stefan Schnitzer}

Department of Biological Sciences, University of Wisconsin, Milwaukee, Wisconsin Jurgi Cristóbal-Azkarate

Laboratorio de Salud de Fauna Silvestre, Centro de Investigaciones Tropicales, Universidad Veracruzana, Siete de Enero \#12, Col. Felipe Carrillo Puerto, Xalapa, CP 91080 Veracruz, Mexico

\section{Abstract}

Lianas are important components in the dynamics of tropical forests and represent fallback foods for some primates, yet little is known about their impact on primate ecology, behavior or fitness. Using 2 yr of field data, we investigated liana consumption and foraging effort in four groups of howler monkeys (two in bigger, more conserved forest fragments and two in smaller, less conserved fragments) to assess whether howler monkeys use lianas when and where food availability is scarce, and how liana consumption is related to foraging effort. Howler monkeys in smaller fragments spent more time consuming lianas and liana consumption was negatively related to the consumption of preferred food resources (fruit and Ficus spp.). Further, travel time was positively related to liana feeding time, but not to tree feeding time, and howler monkeys visited a greater number of food patches when feeding from liana leaves than when feeding from tree leaves. Our results suggest that these increases in foraging effort were related to the fact that lianas are mainly a source of leaves, and that liana patch size was probably smaller than tree patch size. While these results were clear when analyzing all four groups combined, however, they were not always significant in each of the groups individually. We suggest that this may be related to the differences in group size, patch size and the availability of resources among groups. Further studies are necessary to assess whether these dietary and behavioral adjustments negatively impact on the fitness and conservation of primates in fragments.

The loss, degradation and fragmentation of original habitat represent major threats for the conservation of biodiversity, especially in tropical forests (e.g., Andrén 1994, Brook et al. 2003, Laurance et al. 2006). Arboreal primates are particularly vulnerable to these threats (e.g., Cowlishaw \& Dunbar 2000) and, as a consequence, half the world's primate species are currently threatened with extinction (IUCN 2010). Primate populations in tropical forest fragments face not only a reduction in the amount of habitat available and an increase in isolation, but also significant modifications to the availability of food resources, including the loss of big fruiting trees (Medley 1993, Tutin 1999, Arroyo-Rodríguez \& Mandujano 2006).

In contrast to big trees, the abundance and diversity of lianas (here we use the term to refer to both woody and herbaceous vines) tend to be higher in disturbed and fragmented forests (Putz 1984, Hegarty \& Caballé 1991, Laurance et al. 1998, Schnitzer \& Bongers 2002, Schnitzer \& Carson 2008). Tropical lianas reproduce during periods unfavorable to trees, providing new leaves, flowers and fruit during periods of resource scarcity (e.g., Opler et al. 1991, Morellato \& Leitão-Filho 1996), and have a much higher growth rate during the dry season than trees (Schnitzer 2005). Through such competitive advantages lianas can provide important food resources for primates at sites where, and/or during times when, food availability is scarce (Onderdonk \& Chapman 2000, Preece 2006, Moscovice et al. 2007, Marshall et al. 2009). Indeed, several liana species have been identified as fallback foods in the diet of primates (defined as abundant foods of relatively low quality that are used during periods of low overall food availability, Marshall et al. 2009). Consequently, lianas might be key selective forces for primate ecology, evolution and distribution, and their availability may be related to the carrying capacity of their forest habitats (Preece 2006, reviewed by Marshall et al. 2009). 
Howler monkeys (Alouatta spp.) have been reported to use lianas as a supplementary resource when food availability is scarce within forest fragments (Chiarello 1994, Rodríguez-Luna et al. 2003, Asensio et al. 2007, Cristóbal-Azkarate \& Arroyo-Rodríguez 2007). For example, Rodríguez-Luna et al. (2003) reported an increase in liana consumption from 8.8 to 21.0 percent when the population density of a group of howler monkeys inhabiting an 8.3 ha island in Los Tuxtlas, Mexico, grew from 1.2 ind/ha in 1989 to 6.9 ind/ha in 1997.

Furthermore, Asensio et al. (2007) reported that lianas were an extremely prominent component of the diet of this hyperdense population of howler monkeys ( $33 \%$ of total feeding time - TFT), and that the group also spent significantly more time traveling than other groups in the region. As data on howler monkey ranging behavior shows that they travel almost exclusively to get to food resources (Milton 1980), such increases in travel time are likely to reflect significant increases in foraging effort. Despite these interesting observations, and the probable importance of lianas as a food resource for primates in fragments, little is known about the impact that liana consumption may have on primate ecology, behavior or fitness. Such information is important for our understanding of primate ecology and evolution, as well as to enable us to design effective conservation and management strategies.

Here we use data collected from two independent field studies on the feeding ecology of mantled howler monkeys (Alouatta palliata) inhabiting four different forest fragments in Los Tuxtlas, Mexico, to test two main hypotheses: (1) howler monkeys use lianas as supplementary food resources when food availability is scarce; and (2) liana consumption increases foraging effort.

\section{Methods}

\section{Study species}

The Mexican mantled howler monkey (Alouatta palliata mexicana) has a natural distribution ranging from southeast Mexico to southern Guatemala (Rylands et al. 2006). Largely due to habitat loss and fragmentation, this subspecies is currently classified as 'Critically Endangered' by the International Union for the Conservation of Nature (Cuarón et al. 2008).

Howler monkeys perform most of their activities in the upper canopy (Mendel 1976) and preferentially obtain food resources from big trees (Dunn et al. 2009). They also feed from non-arboreal life forms such as lianas, however, although generally in smaller quantities (e.g., mean \pm SD liana consumption in a review of 21 studies carried out in Los Tuxtlas $=2.8 \pm 7.3 \%$ TFT, Cristóbal-Azkarate \& Arroyo-Rodríguez 2007). Although howler monkeys have traditionally been considered the most folivorous of the New World monkeys (e.g., Eisenberg et al. 1972), most reports of the howler monkey diet suggest that they spend about half of their feeding time consuming fruits (Milton 1980, Estrada 1984, Asensio et al. 2007, Dunn et al. 2009), generally being as frugivorous as possible and as folivorous as necessary (Silver et al. 1998, Ostro et al. 1999, Dunn et al. 2009, 2010). Figs (Ficus spp.) have consistently been described as the most important plant taxon in the diet of howler monkeys (Bicca-Marques 2003), representing up to 65 percent of TFT in Los Tuxtlas (CristóbalAzkarate \& Arroyo-Rodríguez 2007). For these reasons, the availabilities of big trees, fruit and figs have all been suggested to be key elements for the persistence of howler monkeys in forest fragments (Arroyo-Rodríguez \& Mandujano 2006, Arroyo-Rodríguez et al. 2007, Dunn et al. 2009, 2010).

\section{Study site}

The Los Tuxtlas Biosphere Reserve is in the southeast of the state of Veracruz, Mexico $\left(18^{\circ} 8^{\prime}-45^{\prime} \mathrm{N}, 94^{\circ} 37^{\prime}-\right.$ $95^{\circ} 22^{\prime} \mathrm{W}$ ). The original dominant vegetation in the region $<700 \mathrm{~m}$ asl was tropical rain forest, but the area has been severely fragmented over the last $40 \mathrm{yr}$ (Dirzo \& García 1992) and the remaining landscape is composed of an archipelago of different sized forest fragments that vary in degree of isolation and vegetation structure (Cristóbal-Azkarate et al. 2005, Arroyo-Rodríguez \& Mandujano 2006, Arroyo-Rodríguez et al. 2008). 
The climate is warm and humid, with a mean annual temperature of $25^{\circ} \mathrm{C}$ and rainfall between 3000 and $4600 \mathrm{~mm}$. There is a marked dry season between March and May (Soto \& Gama 1997). Long-term records of phenological data in the region (Estrada \& Coates-Estrada 1991, 2001, Ibarra-Manríquez \& Oyama 1992, Estrada et al. 1999) consistently show that there are two distinct peaks in fruit production in the region: a primary peak at the end of the dry season-beginning of the rainy season (April-June), and a shorter, less intense secondary peak in the wet season (August-October). Fruit production abruptly falls to very low levels between November and March. Young leaf production is year round, but is at its greatest during the dry season and the beginning of the wet season (March-June) (Figure S1).

\section{Study fragments and groups}

Data were collected during two independent field studies on the feeding ecology of howler monkeys. Case Study 1 (Asensio et al. 2007) analyzed two groups living in different-sized old-growth forest fragments: Playa Escondida (PLA: 40 ha; $18^{\circ} 31^{\prime} \mathrm{N}, 95^{\circ} 03^{\prime} \mathrm{W}$ ) and Agaltepec Island (AGA: 8.3 ha; 1827' N, 9502' W). At the time of the study the PLA group contained 7 individuals, 2 adult males, 2 adult females, 2 juveniles and 1 infant, while the AGA group contained 59 individuals, 19 adult males, 21 adult females, 11 juveniles and 8 infants. The study group in PLA shared its forest fragment with three other groups, whereas there was only one group in AGA. Although demographic data were not collected from the other groups in PLA, the overall population density has previously been reported to be 1.05 ind/ha (Serio-Silva \& Rico-Gray 2002), while in AGA population density was $9.5 \mathrm{ind} / \mathrm{ha}$. As a consequence, population density was probably around nine times higher in AGA than in PLA. Case Study 2 (Dunn et al. 2009, 2010) analyzed two additional groups in two further old-growth forest fragments: Rancho Huber (RH: 244 ha; $18^{\circ} 36^{\prime} \mathrm{N}, 95^{\circ} 06^{\prime} \mathrm{W}$ ) and Ruiz Cortines 3 (RC3: 7.2 ha; $18^{\circ} 36^{\prime} \mathrm{N}, 9^{\circ} 07^{\prime} \mathrm{W}$ ), which were similar in terms of age-gender composition (three adult males, three adult females, two infants in each group and one additional juvenile in the RH group: Dunn et al. 2009). Whereas the RH fragment was occupied by a total of five groups (Cristóbal-Azkarate et al. 2005), RC3 was only occupied by one group. Again, demographic data were not collected from the other groups in the $\mathrm{RH}$ fragment, but the overall population density has previously been reported to be 0.12 ind/ha (Cristóbal-Azkarate et al. 2005), while in RC3 population density was 1.10 ind/ha. Therefore, population density was probably also about nine times higher in RC3 than in $\mathrm{RH}$.

\section{Vegetation attributes within home ranges}

We calculated the home range area of each of the study groups at the end of each study using the 95 percent Kernel method (Kie et al. 1996). Data points were included from all trees and lianas visited during the study, as well as the start and end positions of the howler groups each morning and afternoon (see Dunn et al. 2009 for further details).

We then sampled the vegetation within each home range following similar methods in each case study, but with a greater sampling effort in Case Study 2. In PLA and AGA (Case Study 1), we randomly located ten $50 \times 2 \mathrm{~m}$ transects and identified and counted all trees with diameter at breast height ( $\mathrm{dbh}) \geq 10 \mathrm{~cm}$ and all encountered lianas (regardless of dbh). In RH and RC3 (Case Study 2), we randomly located forty $50 \times 2 \mathrm{~m}$ transects and identified and counted all trees with $\mathrm{dbh} \geq 10 \mathrm{~cm}$ and all lianas with $\mathrm{dbh} \geq 2.5 \mathrm{~cm}$.

To characterize fruit availability in the home range of each group, we carried out a literature search of all the available studies (published articles, book chapters and theses) on the diet of Alouatta palliata in Los Tuxtlas (Cristóbal-Azkarate \& Arroyo-Rodríguez 2007). We were able to determine the items consumed for 155 species (defined as consumable species), of which 69 species are reported as sources of fruit (defined as consumable fruit species - CFS, see Dunn et al. 2010 for a list of species). We then estimated species richness, number of stems, and dominance (sum of basal area) of CFS, fig trees and big trees of consumable species (defined as those with a dbh $>60 \mathrm{~cm}$ ) in the home range of each group. Finally, to investigate whether howler monkeys used 
lianas as supplementary food resources where food availability was scarce, we examined the liana species available in the home range of each group and compared these to the liana species consumed.

\section{Behavioral observations}

In PLA and AGA (Case Study 1), focal observation sessions of 5-h were made on a random rotation over a period of 11 consecutive months (August 1997 to June 1998) with 55 observation days ( 325 focal h) in PLA and 74 observation days (415 focal h) in AGA. In RH and RC3 (Case Study 2), animal focal observation sessions of 2-h were made three times per day on a random rotation over a period of 12 consecutive months (February 20062007), for a total of 80 non-consecutive observation days and $480 \mathrm{~h}$ per group (see Asensio et al. 2007 and Dunn et al. 2009 for further details).

In both case studies, behavioral observations were categorized as one of the following: resting (sleep or static without interaction), feeding (inspection of food, bringing food to mouth, chewing and swallowing, moving while feeding within a food patch), and traveling (movement to a new area or food patch), which are reported in terms of percentage of total activity budget. As howler monkeys travel almost exclusively to get to food resources (Milton 1980), we used travel time as a proxy of foraging effort in this study. During feeding we recorded the food item consumed: fruit, flower, leaf or other (shoots, petioles or bark) and we reported feeding time in terms of percentage of total feeding time (\%TFT), except when reporting leaf feeding time from lianas and trees, in which case we reported percentage of total leaf feeding time (\%TLFT: defined as the percentage of total feeding time devoted to leaves).

Food patches were defined as individual trees or lianas from which the focal individuals fed. When counting the number of food patches visited, however, if the focal animal left a food patch and returned to it without feeding from a different patch, then this was considered as only one food patch. Patch residence time was defined as the time spent feeding by focal individuals in any given food patch. If the focal animal stopped eating for less than 5 min and then continued feeding from the same patch, however, then this was recorded as part of the same feeding bout.

\section{Data management and analysis}

As the case studies used different methodologies, we did not directly compare data between studies, only between groups within each case study. We did, however, perform combined analyses using data from all four groups to investigate general tendencies. All statistical tests were performed with JMP software (v. 7.0, SAS Institute Inc., Cary, N.C.) and mean values were reported \pm SD unless otherwise stated.

To analyze the vegetation attributes in the different forest fragments, we calculated mean $( \pm S D)$ values per transect $\left(100 \mathrm{~m}^{2}\right)$ and compared the means between groups within each case study using $t$-tests (Zar 1996).

For the behavioral data, in Case Study 1, we used months as independent replicates for analysis. To reduce data dependency between months, we randomly chose five focal scan follows ( $25 \mathrm{~h}$ ) per month from each group and reported mean values for diet and activity per month. In Case Study 2 we organized our sampling sessions into ten registration periods of $16 \mathrm{~d}$ ( $8 \mathrm{~d}$ per fragment), each of which was separated by at least $7 \mathrm{~d}$ and, therefore, considered to be independent (see Dunn et al. 2010 for further details). In this case, we reported mean values for diet and activity per registration period and used registration periods as independent replicates for analysis.

To determine how howler monkeys use lianas as food resources, we compared liana feeding time, tree feeding time and patch residence time in trees and lianas between groups using two-way ANOVAs (\%TFT or patch residence time $=$ group + life form + group $\times$ life form) and related liana feeding time with fruit feeding time and Ficus spp. feeding time using linear correlations. For these analyses, proportional data were normalized 
using the arcsine square root transformation, and patch residence time was normalized using a logarithmic transformation.

Subsequently, to investigate the relationship between liana consumption and foraging effort, we related liana feeding time with travel time and tree feeding time with travel time using linear regression analyses, and tested whether the liana - travel slopes were steeper than the tree - travel slopes, for each group separately and combined using $t$-tests (Zar 1996). The same procedure was used to relate: (1) the number of liana patches visited with travel time and the number of tree patches visited with travel time; (2) liana leaf feeding time with travel time and tree leaf feeding time with travel time; and (3) liana leaf feeding time with the number of patches visited and tree leaf feeding time with the number of patches visited.

\section{Results}

\section{Vegetation attributes and food availability within the fragments}

The home range area and vegetation characteristics of each home range are summarized in Table 1. In general, the larger fragments ( $\mathrm{RH}$ and PLA) were found to contain a higher availability of preferred food resources for howler monkeys (i.e., higher species richness, stem density and basal area of CFS, Ficus spp., and big trees of consumable species) than their smaller counterparts (RC3 and AGA). These differences were not significant in all cases, however, and less clear in Case Study 1 (Table 1). Lianas showed the opposite pattern, with significantly higher species richness of lianas in the smaller fragments (RC3 and AGA) than in their larger pairs (RH and PLA), and significantly higher stem density and basal area of lianas in RC3 than in RH (Table 1).

Table 1. General habitat characteristics sampled within the home range of four groups of howler monkeys in different forest fragments in Los Tuxtlas, Mexico. We report mean ( \pm SD) data per $100 \mathrm{~m}^{2}$ in terms of the species richness, number of stems and basal area for consumable fruit species (CFS), Ficus, big trees of consumable species $(\mathrm{dbh}>60 \mathrm{~cm})$ and lianas.

\begin{tabular}{|l|l|l|l|l|}
\hline & Case Study 1 & & Case Study 2 & \\
\hline & PLA (bigger) & AGA (smaller) & RH (bigger) & RC3 (smaller) \\
\hline Fragment size (ha) & 40 & 8.3 & 244 & 7.2 \\
\hline Home range area (ha) & 14.7 & 8.3 & 89.5 & 5.8 \\
\hline CFS & & & & \\
\hline No. Species & $2.20 \pm 1.35$ & $1.10 \pm 1.10 \mathrm{c}$ & $3.53 \pm 1.40$ & $2.80 \pm 1.30 \mathrm{c}$ \\
\hline Stems & $2.40 \pm 1.26$ & $1.20 \pm 1.14 \mathrm{c}$ & $3.59 \pm 1.89$ & $4.65 \pm 2.29 \mathrm{c}$ \\
\hline Basal area $\left(\mathrm{m}^{2}\right)$ & $0.92 \pm 1.26$ & $0.56 \pm 1.10$ & $0.61 \pm 0.81$ & $0.28 \pm 0.28 \mathrm{c}$ \\
\hline Big trees of consumable spp. & & & & \\
\hline No. Species & $1.12 \pm 0.90$ & $1.00 \pm 0.74$ & $0.26 \pm 0.49$ & $0.21 \pm 0.46$ \\
\hline Stems & $1.10 \pm 1.10$ & $1.00 \pm 0.94$ & $0.70 \pm 0.82$ & $0.23 \pm 0.53 \mathrm{~d}$ \\
\hline Basal area $\left(\mathrm{m}^{2}\right)$ & $0.90 \pm 1.30$ & $0.65 \pm 1.08$ & $0.49 \pm 0.82$ & $0.13 \pm 0.35 \mathrm{c}$ \\
\hline Ficus spp. & & & & \\
\hline No. Species & $0.50 \pm 0.71$ & $0.40 \pm 0.52$ & $0.28 \pm 0.51$ & $0.08 \pm 0.27 \mathrm{c}$ \\
\hline Stems & $0.50 \pm 0.71$ & $0.40 \pm 0.52$ & $0.31 \pm 0.53$ & $0.08 \pm 0.27 \mathrm{c}$ \\
\hline Basal area $\left(\mathrm{m}^{2}\right)$ & $0.66 \pm 1.28$ & $0.43 \pm 0.93$ & $0.29 \pm 0.79$ & $0.001 \pm 0.01 \mathrm{c}$ \\
\hline Lianas & & & & \\
\hline No. Speciesa & $5.3 \pm 1.08$ & $8.10 \pm 2.08 \mathrm{~d}$ & $0.50 \pm 0.75$ & $1.00 \pm 1.03 \mathrm{c}$ \\
\hline Stemsa & $15.90 \pm 3.65$ & $13.80 \pm 5.60$ & $0.53 \pm 0.82$ & $1.13 \pm 1.18 \mathrm{~d}$ \\
\hline Basal area $\left(\mathrm{m}^{2}\right) \mathrm{b}$ & - & - & $0.0009 \pm 0.0002$ & $0.02 \pm 0.08 \mathrm{c}$ \\
\hline
\end{tabular}

Data was obtained from ten $50 \times 2 \mathrm{~m}$ transects in PLA and AGA and forty $50 \times 2 \mathrm{~m}$ transects in RH and RC3. 
${ }^{a}$ In Case Study 1, lianas were recorded regardless of dbh, while in Case Study 2 only lianas with $\mathrm{dbh}>2.5 \mathrm{~cm}$ were recorded.

${ }^{b}$ As dbh was not recorded in Case Study 1 , no basal area could be calculated.

${ }^{c}$ Differences between fragments were significant at the $P<0.05$ level,

${ }^{d}$ differences between fragments were significant at the $P<0.01$ level.

\section{Foraging pattern}

In total, howler monkeys used 36 species of lianas from 18 families as food resources (Table S1). In both case studies, the groups living in smaller fragments consumed a greater number of liana species than their counterparts in bigger fragments (Table S1). The number of liana species consumed, as a percentage of the total number of plant species consumed by each group was 33.9 percent (19/56), 22.4 percent (11/49), 25.5 percent $(14 / 55)$ and 14.7 percent $(5 / 34)$ in AGA, PLA, RC3 and RH, respectively, while liana feeding time totalled $28.5 \%$ TFT, $4.9 \%$ TFT, $10.7 \%$ TFT and 3.3\% TFT in AGA, PLA, RC3 and RH, respectively.

Five liana species were consumed in the smaller AGA fragment that were also available in the larger PLA fragment, yet not consumed there, and three liana species were consumed in the smaller RC3 fragment that were also available in the larger $\mathrm{RH}$ fragment yet never consumed there (Table S1). This was never true the other way round, i.e., there were no liana species that were consumed in bigger fragments that were also available in smaller fragments and not consumed there (Table S1).

Lianas were principally a source of leaves in both case studies, but were also used occasionally as sources of fruit and flowers (Fig. 1). Over all four study groups, the mean\% TFT per sampling session spent feeding on trees averaged $88.2 \pm 14.4$ percent (range $=46.3-100 \%$ ) and on lianas averaged $11.3 \pm 14.1$ percent (range $=0$ 53.7\%). Indeed, a significantly higher\% TFT was spent feeding from trees than from lianas by all groups $(P<0.001$; Fig. 2A). Additionally, the interacting terms in the ANOVA (life form $\times$ group) were significant in both case studies (Case Study 1: $F=45.2, P<0.001$; Case Study 2: $F=25.9, P<0.001$ ) indicating that the groups in smaller fragments (AGA and RC3) spent a significantly lower\% TFT feeding from trees, and a significantly higher\% TFT feeding from lianas than their counterparts (Fig. 2A).

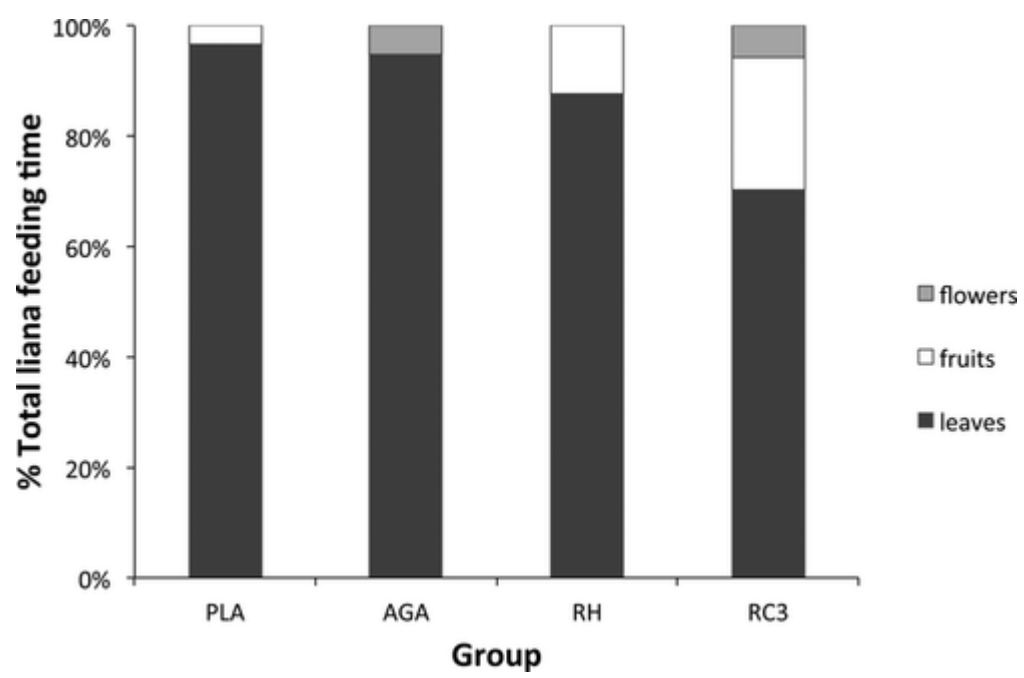

Figure 1. Percentage of liana feeding time spent consuming different items by four groups of howler monkeys inhabiting different forest fragments in Los Tuxtlas, Mexico. 

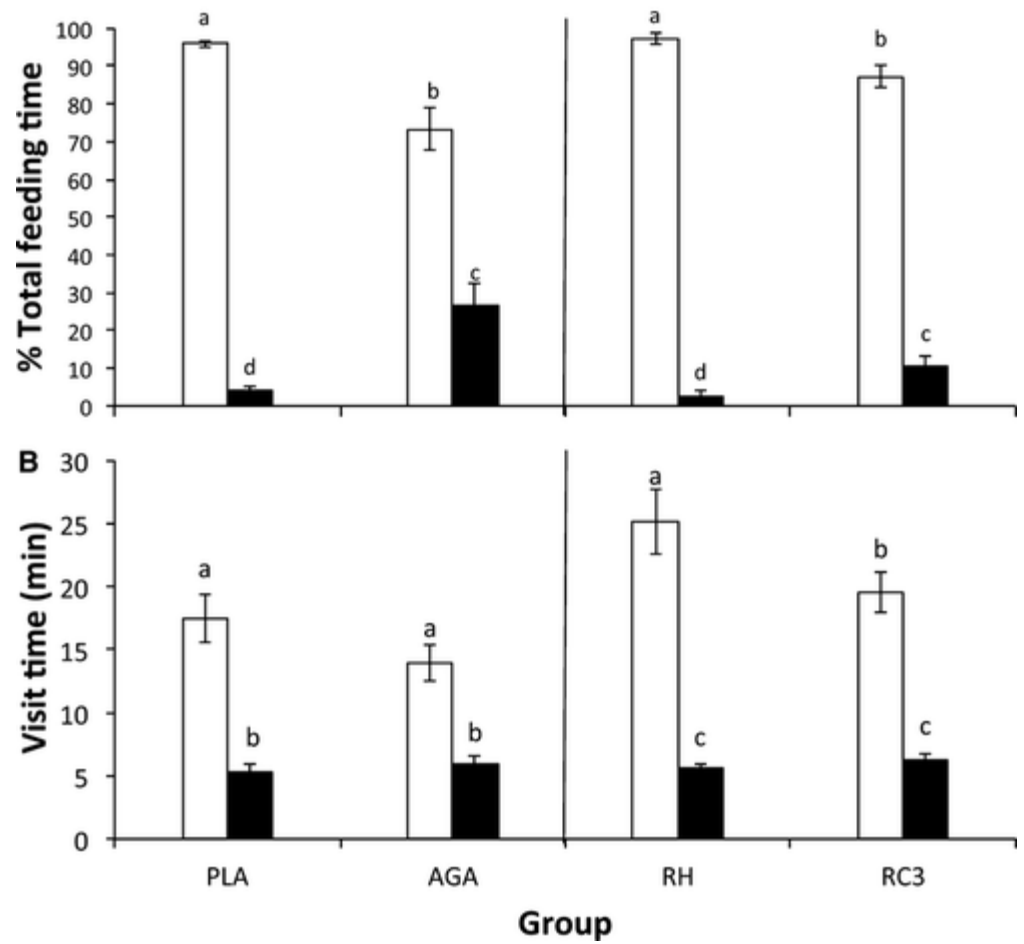

Figure 2. Mean ( \pm SE) percentage of time feeding on trees and lianas $(A)$ and average time during a single visit $(B)$ in four howler monkeys' groups inhabiting different forest fragments at Los Tuxtlas, Mexico. We independently analyzed PLA vs. AGA, and RH vs. RC3. Different letters above bars indicate significant differences (Tukey HSD Test, $P<0.05)$.

Further, in all four study groups, patch residence time was significantly longer in trees than in lianas (Fig. 2B; $P<0.001$ in all cases). As the interacting term in the ANOVA was significant in Case Study 1 $(F=13.04, P<0.001)$, and very close to significant in Case Study $2(F=3.60, P=0.06)$, this indicates that the groups in smaller fragments ( $A G A$ and RC3) exhibited a shorter patch residence time in trees than their counterparts, and a longer patch residence time in lianas than their counterparts (Fig. 2B).

Overall, howler monkeys consumed lianas more frequently during months of low fruit consumption, which also corresponded with the months of low fruit availability reported in Los Tuxtlas (Figures. S1 and S2). Indeed, grouping the data set from all four groups, the consumption of lianas was negatively related to the consumption of fruit $(r=-0.52, P<0.001)$ and Ficus spp. $(r=-0.61, P<0.001)$. When considering each group separately, however, only in PLA $(r=-0.65, P<0.001)$ and AGA $(r=-0.75, P<0.001)$ were the consumptions of lianas and Ficus spp. negatively related, and only in $\mathrm{RH}$ were the consumption of lianas and fruits negatively related $(r=-0.61, P<0.05)$ (Figure $\mathrm{S} 2$ ).

\section{Liana feeding time and travel time}

Travel time was positively related to both liana feeding time and liana leaf feeding time, but negatively related to tree feeding time and not related to tree leaf feeding time for the four howler groups combined (Figs. $3 \mathrm{~A}$ and B). In both cases, the slopes were significantly different (Fig. $3 \mathrm{~A}: t=5.12$, $\mathrm{df}=38, P<0.0001$; Fig. $3 \mathrm{~B}$ : $t=43.4$, $\mathrm{df}=38, P<0.0001$ ). In both cases, however, the trends were driven primarily by the AGA group, where the liana - travel slope $(b=0.141)$ was significantly different from the tree - travel slope $(b=-0.141)(t=4.74$, $\mathrm{df}=9, P=0.001)$, and the liana leaf - travel slope $(b=0.144)$ was significantly different than the tree leaf travel slope $(b=-0.518)(t=2.48, d f=9, P=0.04)$. Neither the liana - travel/tree - travel slopes nor the liana leaf - travel/tree leaf - travel slopes were statistically different in PLA, RC3, or RH ( $P>0.15$ in all cases). 

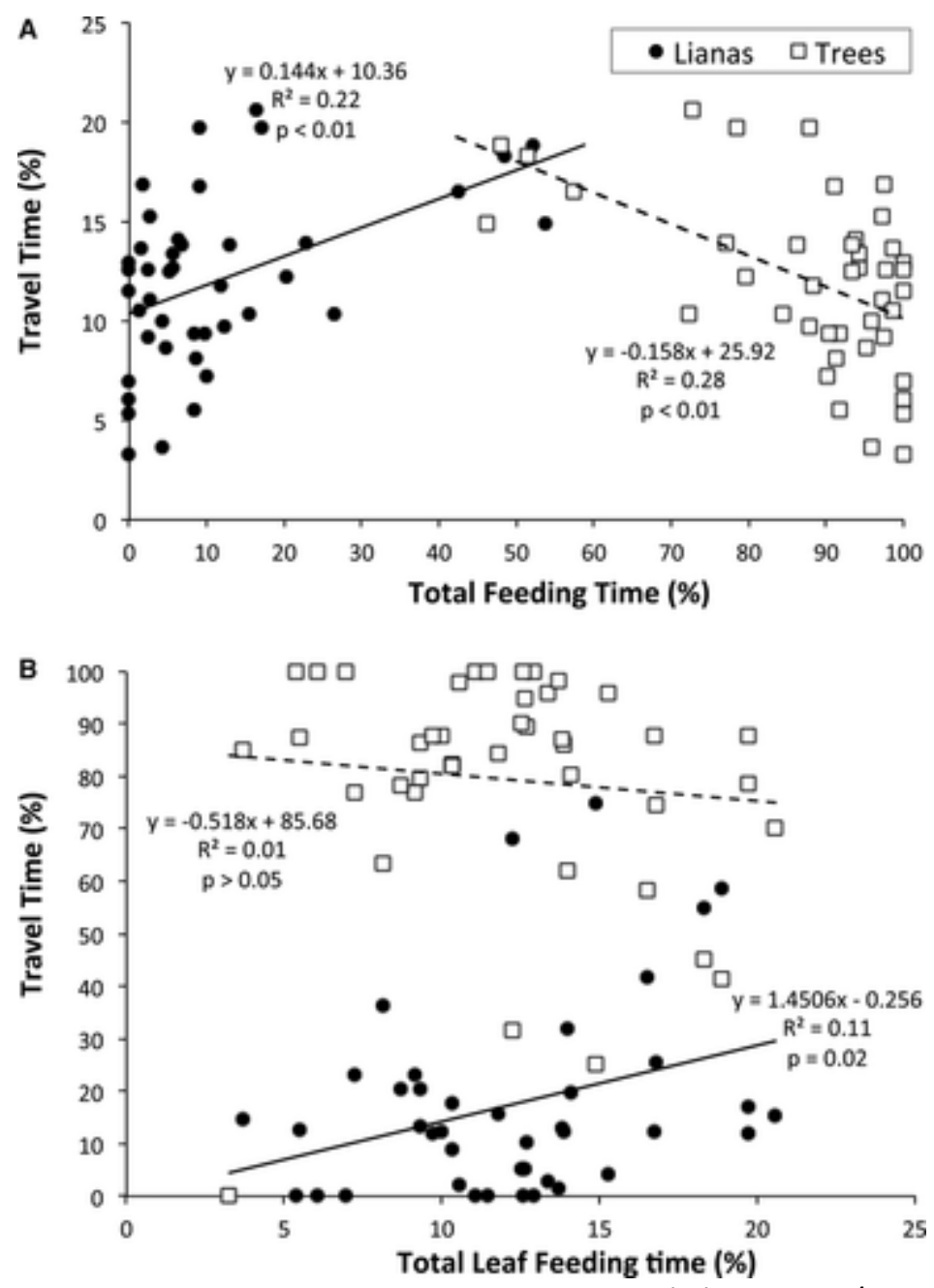

Figure 3. Relationship between travel time (\%) and tree/liana feeding time (A) and tree/liana leaf feeding time (B) in four howler monkey groups in Los Tuxtlas, Mexico.

Further, howler monkeys visited a significantly greater number of patches when feeding from liana leaves than when feeding from tree leaves, and these slopes were significantly different $(t=2.46, \mathrm{df}=38, P=0.01$; Fig. $4 \mathrm{~A}$ ). This trend was again driven by the AGA group ( $t=2.60, \mathrm{df}=7, P=0.04)$, as in PLA, RC3, and RH the slopes were not significantly different $(P>0.15$ in all cases). 

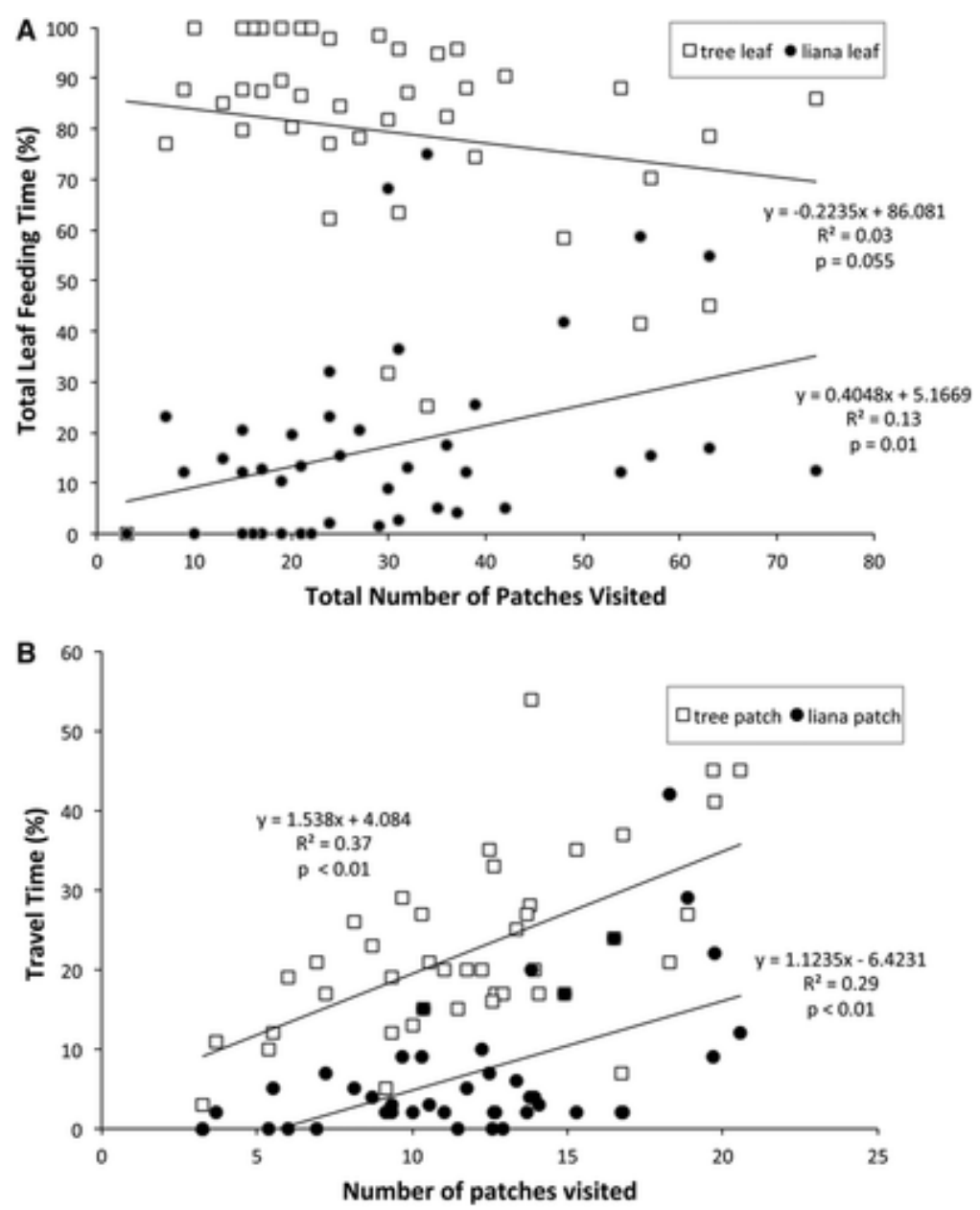

Figure 4. Relationship between leaf feeding time (\%TLFT) and total number of patches visited (A) and travel time (\%) and number of liana and tree patches visited (B) in four howler monkey groups in Los Tuxtlas, Mexico.

Finally, when analyzing the four groups collectively, travel time was positively related to the number of liana patches visited and the number of tree patches visited, and these slopes were similar $(t=0.97, \mathrm{df}=38, P=0.34$; Fig. 4B). A similar tendency was observed when analyzing each group separately ( $P>0.55$ in all cases).

\section{Discussion}

Our results support the idea that lianas are fallback foods for primates (Marshall et al. 2009); in this study lianas provided supplementary food resources for howler monkeys both where and when food availability was scarce. Howler monkeys in smaller, more degraded forest fragments spent significantly more of their feeding time consuming a greater number of liana species and spent significantly longer periods feeding from each liana patch than those in bigger, more conserved forest fragments. Further, liana feeding time was negatively related to the time spent feeding from (and, probably, the availability of) preferred food resources (i.e., fruit and Ficus spp.). Despite the importance of lianas as fallback foods for howler monkeys, however, our results suggest that liana consumption is positively related to foraging effort, and that liana foraging results in significantly more travel time than does tree foraging.

If liana consumption increases foraging effort in howler monkeys, three non-mutually exclusive hypotheses could explain this observation: (1) lianas are mainly a source of leaves for howler monkeys, and animals may be required to visit more food sources and travel more when feeding from greater quantities of leaves; (2) the distribution of lianas within the forest fragments differs from the distribution of trees, resulting in greater 
foraging effort; and/or (3) lianas generally offer a lower quantity of food resources than trees ( $<5 \%$ of total community biomass and $<20 \%$ total forest leaf area; Putz 1983) and smaller food patches are likely to be depleted more quickly, forcing primates to move more frequently among patches (e.g., Suarez 2006).

Our data are consistent with the first hypothesis. Animals are thought to diversify food resources when consuming leaves to obtain the best complement of nutrients (the nutrient constraint hypothesis; Westoby 1978) and to avoid an overload of particular toxins or digestibility reducing compounds (the detoxification limitation hypothesis; Freeland \& Janzen 1974). Doing so is thought to increase foraging effort in primates (e.g., Suarez 2006). Indeed, leaf consumption has been positively related to diet diversity (Dunn et al. 2010) and feeding effort in howler monkeys (Dunn et al. 2009, 2010). When we isolated leaf consumption from flower and fruit consumption and compared trees and lianas, however, liana leaf consumption increased travel time significantly more than tree leaf consumption. Therefore, while leaf consumption is probably related to increases in foraging effort in howler monkeys, it is probably not leaf consumption per se that is responsible for increasing foraging effort when howler monkeys feed from lianas.

Our data does not support the second hypothesis. Travel time increased in a similar way with the number of liana patches visited as with the number of tree patches visited, which suggests that foraging effort was not associated with the distribution of these different food resources.

Our data are consistent with the third hypothesis. Indeed, when feeding from liana leaves howler monkeys were required to visit more food patches than when feeding from tree leaves and patch residence time was significantly lower when feeding from lianas than when feeding from trees. This hypothesis seems the most likely to explain why foraging effort was significantly higher when feeding from liana leaves than when feeding from tree leaves. However, an important question remains: why were these results significant when we carried out combined analyses of all four groups, yet not in all of the groups individually?

Firstly, the relationship between liana feeding time and foraging effort may depend on group size, which differed considerably among groups. The ecological constraints model proposes that an increase in group size will generally lead to increases in patch depletion rate and foraging effort as a result of scramble competition (Janson 1988, Wrangham et al. 1993, Chapman \& Pavelka 2005). If group size, however, which was particularly high in AGA, had a significant effect on patch depletion rate and, therefore, foraging effort, we would have expected a significantly lower patch residence time in this group when feeding from both trees and lianas. In fact, in both of the smaller fragments patch residence time was significantly lower when feeding from trees than in the bigger fragments, but patch residence time was significantly higher in the smaller fragments when feeding from lianas. The fact that howler monkeys in AGA have previously been observed to forage in subgroups (Dias \& Rodríguez-Luna 2006, Asensio et al. 2007) is also relevant to this discussion and further investigation is required to determine how subgroup size and foraging group dynamics may affect patch depletion and foraging effort. The difference in patch residence time between groups may also have been related to differences in food patch size between fragments. In this sense, we found that trees were generally bigger in the bigger fragments, while lianas were bigger in smaller fragments (Table 1). Consequently, patch size may have interacted with group size to determine the differences in foraging effort we observed between groups.

Secondly, the relationship between liana feeding time and foraging effort probably depends on the availability of food resources, which was not constant between fragments. Optimal foraging theory predicts that as preferred food items become more limited, more less-preferred foods will be included in the diet (classical prey model; MacArthur \& Pianka 1966) and patch residence time will increase (marginal value theorem; Charnov 1976). In this sense we found that howler monkeys in smaller, more degraded forest fragments consumed more liana species, including species that were available, yet not consumed, in the more conserved fragments. As howler monkeys in smaller fragments are less able to be selective, they may increase the number 
of species they consume, which increases foraging effort. Further, howler monkeys in smaller fragments spent significantly more time feeding from each liana patch. The decision of when to leave a patch and start searching for a different one, therefore, probably depends not only on group size and patch size, as mentioned above, but also on the overall profitability of the environment.

Finally, liana feeding time may be required to reach some kind of threshold before any significant effect on foraging effort is observed. This seems questionable, however, as liana feeding time and foraging effort were significantly related in the combined analyses, despite liana feeding time being relatively low. Therefore, perhaps our sample size was not big enough for the statistical tests to work in the case of individual groups or, alternatively, perhaps AGA is an extreme case and this is why this group generally drove the relationships between feeding time and foraging effort. Further research, with more groups, would undoubtedly bring more detailed insight into the effects of liana consumption on howler monkey foraging effort.

Milton (2000) has proposed that howler monkeys use a network of arboreal pathways in the forest to find and monitor the availability and phenological status of primary food resources such as fig trees. These arboreal pathways allow them to keep their travel costs to a minimum and maximize the possibility of encountering highquality foods by avoiding random search. We suggest that in bigger, more profitable forest fragments howler monkeys may use lianas as an opportunistic source of additional nutrients when they are encountered along pathways, whereas in smaller fragments, where lianas represent a more significant component of the diet, they may be forced to divert from these pathways and randomly search for lianas, which may imply significant increases in foraging effort (cf. Garber 2000).

Fallback foods are frequently the primary determinant of primate carrying capacity in forest habitats (Marshall et al. 2009). Thus, special attention should be taken to ensure that lianas are not negatively affected by forest management practices, such as the cutting of liana stems prior to logging to reduce collateral damage when trees are felled (Schnitzer \& Bongers 2002, Meijaard et al. 2005). Further, more detailed studies are required to fully establish the precise ecological mechanisms that may lead to increases in foraging effort when primates consume lianas, and the consequences that these increases in foraging effort may have for howler monkey fitness. In this sense, Dunn (2009) found that feeding effort was positively related to fecal glucocorticoid levels in howler monkeys, suggesting that increases in travel time may have negative consequences for fitness. Further studies are required, however, relating liana consumption, foraging effort, survival and/or reproduction to fully establish the effects of liana consumption on howler monkey fitness. Such information is important for our understanding of primate ecology and evolution as well as to the conservation and management of endangered primate species, particularly in light of the increasing liana abundance and biomass that appear to be emerging in tropical forests (Schnitzer \& Bongers 2011).

\section{Acknowledgments}

We thank the staff of the 'Parque de la Flora y Fauna Silvestre Tropical' in Catemaco, Mexico, for their company and help during this work, as well as L. Mendoza and B. Gomez for their help in the field. We gratefully acknowledge E. Rodríguez-Luna and the Universidad Veracruzana for the use of their facilities, J. Veà and the Universidad de Barcelona for their support and C. Huber, the Palacios family and the community of Montepio for access to their land. We acknowledge the financial support given by 'Zientzia Politikarako Zuzendaritza' of the Basque Government, Spain (NA), the Postdoctoral Fellowship program from Mahidol University, Thailand (NA), the Fundación BBVA (JD) and the Centro de Investigaciones en Ecosistemas (CIEco-UNAM), Mexico (VAR).

\section{Supporting Information}




\begin{tabular}{|l|l|}
\hline $\begin{array}{l}\text { btp856-sup-0001-TableS1.docWord } \\
\text { document, 123 KB }\end{array}$ & $\begin{array}{l}\text { TABLE S1. Percentages of total feeding time spent consuming } \\
\text { different liana species. }\end{array}$ \\
\hline $\begin{array}{l}\text { btp856-sup-0002-FigureS1.docxWord } \\
\text { document, 57.5 KB }\end{array}$ & FIGURE S1. Plant phenology in Los Tuxtlas, Mexico. \\
\hline $\begin{array}{l}\text { btp856-sup-0003-FigureS2.docxWord } \\
\text { document, 13.7 KB }\end{array}$ & $\begin{array}{l}\text { FIGURE S2. Seasonal variation in the percentage of time } \\
\text { feeding on fruit. }\end{array}$ \\
\hline
\end{tabular}

Please note: The publisher is not responsible for the content or functionality of any supporting information supplied by the authors. Any queries (other than missing content) should be directed to the corresponding author for the article.

\section{References}

Andrén, H. 1994. Effects of habitat fragmentation on birds and mammals in landscapes with different proportions of suitable habitat. Oikos, 71: 355- 366.

Arroyo-Rodríguez, V., and S. Mandujano. 2006. Forest fragmentation modifies habitat quality for Alouatta palliata. Int. J. Primatol., 27: 1079- 1096.

Arroyo-Rodríguez, V., S. Mandujano, and J. Benítez-Malvido. 2008. Landscape attributes affecting patch occupancy by howler monkeys (Alouatta palliata mexicana) in fragmented landscapes at Los Tuxtlas, Mexico. Am. J. Primatol., 70: 69- 77.

Arroyo-Rodríguez, V., S. Mandujano, J. Benítez-Malvido, and C. Cuende-Fantón. 2007. The influence of large tree density on howler monkey (Alouatta palliata mexicana) presence in very small rainforest fragments. Biotropica, 39: 760- 766.

Asensio, N., J. Cristóbal-Azkarate, P. A. D. Dias, J. J. Veà, and E. Rodríguez-Luna. 2007. Foraging habits of Alouatta palliata mexicana in three forest fragments. Folia Primatol., 78: 141- 153.

Bicca-Marques, J. 2003. How do howler monkeys cope with habitat fragmentation? In L. K. Marsh (Ed.) Primates in fragments: ecology and conservation, pp. 283- 303. Kluwer Academics/Plenum Publishers, New York, NY.

Brook, B. W., N. S. Sodhi, and P. K. L. Ng. 2003. Catastrophic extinctions follow deforestation in Singapore. Nature, 424: 420-426.

Chapman, C. A., and M. S. M. Pavelka. 2005. Group size in folivorous primates: ecological constraints and the possible influence of social factors. Primates, 46: 1-9.

Charnov, E. L. 1976. Optimal foraging: the marginal value theorem. Theor. Pop. Biol., 9: 129-136.

Chiarello, A. 1994. Diet of the brown howler monkey Alouatta fusca in a semi-deciduous forest fragment of southeastern Brazil. Primates, 35: 25- 34.

Cowlishaw, G., and R. Dunbar. 2000. Primate conservation biology. University of Chicago Press, Chicago, Illinois.

Cristóbal-Azkarate, J., and V. Arroyo-Rodríguez. 2007. Diet and activity pattern of howler monkeys (Alouatta palliata) in Los Tuxtlas, Mexico: effects of habitat fragmentation and implications for conservation. Am. J. Primatol., 69: 1013-1029.

Cristóbal-Azkarate, J., J. J. Veà, N. Asensio, and E. Rodríguez-Luna. 2005. Biogeographical and floristic predictors of the presence and abundance of mantled howler monkeys (Alouatta palliata mexicana) in the rainforest fragments of Los Tuxtlas, Mexico. Am. J. Primatol., 67: 209- 222.

Cuarón, A. D., A. Shedden, E. Rodríguez-Luna, P. C. de Grammont, and A. Link. 2008. Alouatta palliata ssp. mexicana. In 2008 IUCN Red List of Threatened Species. www.iucnredlist.org. Downloaded on 04 September 2010.

Dias, P. A. D., and E. Rodríguez-Luna. 2006. Seasonal changes in associative behavior and subgrouping patterns of mantled howler monkey males living on an island. Int. J. Primatol., 27: 1635- 1651.

Dirzo, R., and M. Garcia. 1992. Rates of deforestation in Los Tuxtlas, a Neotropical area in southeast Mexico. Conserv. Biol., 6: 84-90. 
Dunn, J. C. 2009. The foraging strategy of alouatta palliata: variations in diet and feeding behaviour associated with food availability (habitat size and seasonality) and their effects on physiological health. PhD Dissertation, University of Barcelona, Barcelona, Spain.

Dunn, J. C., J. Cristóbal-Azkarate, and J. Veà. 2009. Differences in diet and activity pattern between two groups of Alouatta palliata associated with the availability of big trees and fruit of top food taxa. Am. J. Primatol., 71: 654- 662.

Dunn, J. C., J. Cristóbal-Azkarate, and J. Veà. 2010. Seasonal variations in the diet and feeding effort of two groups of howler monkeys in different sized forest fragments. Int. J. Primatol., 31: 887-903.

Eisenberg, J. F., N. A Muckenhim, and R. Rudran. 1972. The relation between ecology and social structure in primates. Science, 176: 863-874.

Estrada, A.. 1984. Resource use by howler monkeys (Alouatta palliata) in the rain forest of Los Tuxtlas, Veracruz, Mexico. Int. J. Primatol., 5: 105- 131.

Estrada, A., and R. Coates-Estrada. 1991. Howling monkeys (Alouatta palliata), dung beetles (Scarabaeidae) and seed dispersal: ecological interactions in the tropical rain forest of Los Tuxtlas, Veracruz, Mexico. J. Trop. Ecol., 7: 459- 474.

Estrada, A., and R. Coates-Estrada. 2001. Species composition and reproductive phenology of bats in a tropical landscape at Los Tuxtlas, Mexico. J. Trop. Ecol., 17: 627- 646.

Estrada, A., S. Juan-Solano, T. Ortíz-Martínez, and R. Coates-Estrada. 1999. Feeding and general activity patterns of a howler monkey (Alouatta palliata) troop living in a forest fragment at Los Tuxtlas, Mexico. Am. J. Primatol., 48: 167- 183.

Freeland, W. J., and D. H. Janzen. 1974. Strategies of herbivory in mammals; the role of plant secondary compounds. Am. Nat., 108: 269- 189.

Garber, P. A. 2000. Evidence for the use of spatial, temporal and social information by some primate foragers. In S. Boinski, and P. Garber (Eds.). On the move: How and why animals travel in groups, pp. 165- 203. University of Chicago Press, Chicago.

Hegarty, E. E., and G. Caballé. 1991. Distribution and abundance of vines in forest communities. In F. E. Putz, and H. A. Mooney (Eds.). The biology of vines, pp. 313-335. Cambridge University Press, Cambridge.

Ibarra-Manríquez, G., and K. Oyama. 1992. Ecological correlates of reproductive traits of Mexican rain forest trees. Am. J. Bot., 79: 383- 394.

IUCN. 2010. 2008 IUCN Red List of Threatened Species. www.iucnredlist.org. Downloaded on 04 September 2010.

Janson, C. H. 1988. Intra-specific food competition and primate social structure: a synthesis. Behaviour, 105: 1- 17.

Kie, J. G., J. A. Baldwin, and C. J. Evans. 1996. Calhome: a programme for estimating animal home ranges. Wildl. Soc. Bull., 24: 342- 344.

Laurance, W. F., L. V. Ferreira, J. M. Rankin-de Merona, and S. M. Laurance. 1998. Rain forest fragmentation and the dynamics of Amazonian tree communities. Ecology, 79: 2032- 2040.

Laurance, W. F., H. E. M. Nasciment, S. G. Laurance, A. Andrade, J. E. L. S. Ribeiro, J. P. Giraldo, T. E. Lovejoy, R. Condit, J. Chave, K. E. Harms, and S. D'Angelo. 2006. Rapid decay of tree-community composition in Amazonian forest fragments. Proc. Natl. Aca. Sci. USA, 103: 19010- 19014.

MacArthur, R. H., and E. R. Pianka. 1966. On the optimal use of a patchy environment. Am. Nat., 100: 603-609.

Marshall, A. J., C. J. Boyko, K. L. Feilen, R. H. Boyko, and M. Leighton. 2009. Defining fallback foods and assessing their importance in primate ecology and evolution. Am. J. Phys. Anthropol., 140: 603-614.

Medley, K. E. 1993. Primate conservation along the Tana River, Kenya: an examination of the forest habitat. Conserv. Biol., 7: 109- 121.

Meijaard, E., D. Sheil, R. Nasi, D. Augeri, B. Rosenbaum, D. Iskandar, T. Setyawati, M. Lammertink, I. Rachmatika, A. Wong, T. Soehartono, S. Stanley, and T. O'Brien. 2005. Life after logging: reconciling 
wildlife conservation and production forestry in Indonesian Borneo. Center for International Forestry Research, Jakarta.

Mendel, F. C. 1976. Postural and locomotor behavior of Alouatta palliata on various substrates. Folia Primatol., 26: 36- 53.

Milton, K. 1980. The foraging strategy of howler monkeys; a study of primate economics. Columbia University Press, New York, $165 \mathrm{p}$.

Milton, K. 2000. Quo vadis? Tactics of food search and group movements in primates and other animals. In S. Boinski, and P. A. Garber (Eds.). On the Move: How and why animals travel in groups, pp. 375- 417. University of Chicago Press, Chicago.

Morellato, P. C., and H. F. Leitão-Filho. 1996. Reproductive phenology of climbers in a southern Brazilian forest. Biotropica, 28: 180- 191.

Moscovice, L. R., M. H. Issa, K. J. Petrelkova, N. S. Keuler, C. T. Snowdon, and M. A. Huffman. 2007. Fruit availability, chimpanzee diet, and grouping patterns on Rubondo Island. Tanzania. Am. J. Primatol., 59: 487-502.

Onderdonk, D. A., and C. A. Chapman. 2000. Coping with forest fragmentation: The primates of Kibale National Park, Uganda. Int. J. Primatol., 21: 587-611.

Opler, P. A., H. G. Baker, and G. W. Frankie. 1991. Seasonality of climbers: a review and example from Costa Rican dry forest. In F. E. Putz, and H. A. Mooney (Eds.). The biology of vines, pp. 377-391. Cambridge University Press, Cambridge.

Ostro, L. E. T., S. C. Silver, F. W. Koontz, T. P. Young, and R. W. Horwich. 1999. Ranging behavior of translocated and established groups of black howler monkeys Alouatta pigra in Belize, Central America. Biol. Conserv., 87: 1818- 190.

Preece, G. 2006. Factors influencing variation in the population densities of Colobus guereza, within selectively logged forest at the Budongo Forest Reserve. In N. E. Newton Fisher, H. Norman, J. D. Paterson, and V. Reynolds (Eds.). Primates of Western Uganda, pp. 23-43. Springer, New York.

Putz, F. E. 1983. Liana biomass and leaf area of a "tierra firme" forest in the rio negro basin, Venezuela. Biotropica, 15: 185- 189.

Putz, F. E. 1984. How trees avoid and shed lianas. Biotropica, 16: 19- 23.

Rodríguez-Luna, E., L. E. Domínguez-Domínguez, J. E. Morales-Mávil, and M. Marunez-Morales. 2003. Foraging strategy changes in an Alouatta palliata mexicana troop released on an island. In L. Marsh (Ed.) Primates in fragments: ecology and conservation, pp. 229-249. Kluwer Academic/Plenum Publishers, New York.

Rylands, A. B., C. P. Groves, R. A. Mittermeier, L. Cortes-Ortiz, and J. J. H Hines. 2006. Taxonomy and distributions of Mesoamerican primates. In A. Garber, P. A. Pavelka, and M. S. M. Luecke (Eds.). New perspectives in the study of Mesoamerican primates: distribution, ecology, behaviour and conservation, pp. 29- 79. Springer, New York.

Schnitzer, S. A. 2005. A mechanistic explanation for global patterns of liana abundance and distribution. Am. Nat., 166: 262- 76.

Schnitzer, S. A., and F. Bongers. 2002. The ecology of lianas and their role in forests. Trends Ecol. Evol., 17: 223- 230.

Schnitzer, S. A., and F. Bongers. 2011. Increasing liana abundance and biomass in tropical forests: emerging patterns and putative mechanisms. Ecol. Lett., 14: 397- 406.

Schnitzer, S. A., and W. P. Carson. 2008. Tropical forest community ecology. Blackwell Publishing, Oxford.

Serio-Silva, J. C., and V. Rico-Gray. 2002. Interacting effects of forest fragmentation and howler monkey foraging on germination and dispersal of fig seeds. Oryx, 36: 266- 271.

Silver, S. C., L. E. T. Ostro, C. P. Yeager, and R. Horwich. 1998. Feeding ecology of the black howler monkey (Alouatta pigra) in Northern Belize. Am. J. Primatol., 45: 263- 279. 
Soto, M., and L. Gama. 1997. Geologia. In R. Vogt, E. Gonzalez-Soriano, and R. Dirzo (Eds.). Historia Natural de Los Tuxtlas, pp. 7-23. UNAM, Mexico.

Suarez, S. A. 2006. Diet and travel costs for spider monkeys in a nonseasonal, hyperdiverse environment. Int. J. Primatol., 27: 411- 436.

Tutin, C. E. G. 1999. Fragmented living: Behavioural ecology of primates in a forest fragment in the Lopé Reserve, Gabon. Primates, 40: 249- 265.

Westoby, M. 1978. What are the biological bases of varied diets? Am. Nat., 112: 627-631.

Wrangham, R. W., J. Gittleman, and C. A. Chapman. 1993. Constraints on group size in primates and carnivores: population density and day-range as assays of exploitation competition. Behav. Ecol. Sociobiol., 32: 199- 210.

Zar, J. H. 1996. Biostatistical analysis ( 3rd Edition). Prentice-Hall, Englewood Cliffs, NJ. 